\title{
Breeding Vegetables Adapted to High Temperatures: A Case Study with Broccoli
}

\author{
Mark W. Farnham ${ }^{1,3}$ \\ U.S. Department of Agriculture, Agricultural Research Service, 2700 Savannah Highway, \\ U.S. Vegetable Laboratory, Charleston, SC 29414 \\ Thomas Bjorkman ${ }^{2}$ \\ Department of Horticulture, NYSAES, Cornell University, Geneva, New York 14456
}

Additional index words. Brassica oleracea Italica Group, heat tolerance, environmental stress, vernalization

\begin{abstract}
Breeding a vegetable crop for adaptation to a temperature regime that is higher than the recognized optimum for the species in question is an example of breeding for abiotic stress tolerance. Before embarking on a project to breed for such stress tolerance, we propose that several critical considerations or questions must be addressed. These considerations include the following: 1) What is the effect of the abiotic stress on the crop to be improved; 2) what will be the conditions of the selection environment; 3 ) what germplasm is available that contains the necessary genetic variation to initiate improvement; 4) what breeding scheme will be used to facilitate improvement; and 5) what will be the specific goals of the breeding effort? We use a case study with broccoli to breed for adaptation to high-temperature environments to provide examples of how each of these considerations might be addressed in developing an improvement effort. Based on documented success with this case study in which broccoli quality and performance under high-temperature summer environments has been improved, insights are provided that should be useful to future attempts to breed vegetables more tolerant of an abiotic stress.
\end{abstract}

Breeding is one of the most efficient methods for managing abiotic stress. Some abiotic stresses directly reduce growth. Others affect development in a way that reduces or eliminates the crop's value. An example of the latter is superoptimal temperature stress in broccoli. Breeding for tolerance to this stress has great potential for meeting increased demand by growing in a larger production region.

Most vegetable crops are adapted to a modest range in temperatures with the optimum varying considerably from warm- to coolseason species. Cole crop vegetables (Brassica oleracea L.) are cool-season crops that include broccoli (B. oleracea Italica Group), cauliflower (B. oleracea Botrytis Group), and cabbage ( $B$. oleracea Capitata Group). The optimum temperature range in which to produce these vegetables is between 15 and $18^{\circ} \mathrm{C}$ (Maynard and Hochmuth, 2007). Thus, the cole crops are best adapted to spring and fall in temperate regions or to winter in areas where this season is relatively mild (e.g., Desert Southwest). In favored locales (e.g., the Salinas Valley in California) where a cold ocean abuts a valley and cool, Mediterraneanlike conditions occur nearly year-round, these

Received for publication 23 Feb. 2011. Accepted for publication 19 May 2011.

We acknowledge the excellent technical assistance of Mr. David Couillard and Mr. Joseph W. Shail, Jr., in conducting the field research components of this project.

This paper was part of the colloquium "Improvement of Horticultural Crops for Abiotic Stress Tolerance" held 5 Aug. 2010 at the ASHS Conference, Palm Desert, CA, sponsored by the Vegetable Breeding (VGBR) Working Group, and co-sponsored by the Environmental Stress Physiology (STRS) Working Group.

${ }^{1}$ Research Geneticist.

${ }^{2}$ Associate Professor.

${ }^{3}$ To whom reprint requests should be addressed; e-mail Mark.Farnham@ars.usda.gov. crops can be grown at almost any time of the year.

Broccoli has emerged as the most important cole crop in recent years and U.S. production has a farm-gate value of $\$ 800$ million (United State Department of Agriculture, Economic Research Service, 2010). To produce broccoli throughout the year, broccoli growers have tried to grow this vegetable in temperature regimes that are considered too hot (e.g., 25 to $30{ }^{\circ} \mathrm{C}$ ) for the production of quality heads. To complicate this matter, potentially higher temperatures that may be associated with climate change may make it more difficult for producers to maintain broccoli production in some areas where it was previously well adapted. As a result of these circumstances, most broccoli breeders working to develop either germplasm or elite cultivars adapted to North America have given some attention to breeding broccoli for adaptation to temperatures regimes above the 15 to $18{ }^{\circ} \mathrm{C}$ optimal range.

Breeding a vegetable crop to extend the range of temperature adaptation beyond what exists in current germplasm is one example of breeding for improved abiotic stress tolerance. Breeding for improved abiotic stress tolerance requires addressing several critical considerations:

1) What is the effect of the abiotic stress on the crop to be improved?

2) What will be the conditions of the selection environment?

3) What germplasm is available that contains the necessary genetic variation to initiate improvement?

4) What breeding scheme will be used to facilitate improvement?

5) What will be the specific goals of the breeding effort?

Some of these questions must be addressed as an improvement effort starts, some are more relevant as the effort is well underway, and others must continuously be re-examined as insight of the subject matter is gained and as progress toward objectives is made.

In this presentation, we examine the effort at the U.S. Vegetable Laboratory (USVL) in Charleston, SC, to breed broccoli for adaptation to summer conditions of the southeastern United States and consider this improvement effort as a case study for breeding a vegetable for adaptation to high temperatures. In particular, we focus on how these questions were addressed as this breeding effort was initiated and as it has developed over time.

\section{WHAT IS THE EFFECT OF THE ABIOTIC STRESS ON THE CROP TO BE IMPROVED?}

Several studies have evaluated the effect of low temperatures on the initiation of inflorescence development in broccoli (Fontes et al., 1967; Fontes and Ozbun. 1972; Gauss and Taylor, 1969). Most horticulturists recognize the importance of cold temperatures as necessary for vernalization in biennial vegetables like cabbage or kale; however, few realize that many cultivars of broccoli have a quantitative cold requirement needed to induce flowering (Fontes et al., 1967). Whereas cabbage and kale require temperatures at or below $5{ }^{\circ} \mathrm{C}$ to shift from vegetative to reproductive growth phases, the critical temperature for annual broccoli is significantly higher. Indeed, Wurr et al. (1995) developed a temperature model for broccoli and postulated an upper temperature limit for vernalization at $23.6{ }^{\circ} \mathrm{C}$, above which plants are expected to remain vegetative. Although it is commonly thought that broccoli will prematurely bolt as a result of relatively high temperatures, the opposite is actually the case. Premature bolting in broccoli typically occurs when cold temperatures induce small 
plants to initiate reproductive growth (Miller et al., 1985). Thus, during the vegetative phase, temperatures above the upper limit for vernalization will slow or impede the development of the inflorescence or head.

In broccoli, the main dysfunction induced by high temperatures occurs later in development. Once inflorescence or head development is initiated, relatively high temperatures $\left(\approx 30{ }^{\circ} \mathrm{C}\right)$ arrest head development. Paradoxically, such temperatures can be optimal for vegetative growth (Bjorkman and Pearson, 1998). It is unknown whether genotypes performing better in warm climates have a higher temperature threshold for meeting the chilling requirement or simply a smaller absolute requirement. The typical flaws that result include incomplete head development, uneven bead size, bracting in heads, and rough head surface. It is this sensitivity to warm temperatures near harvest, e.g., during heading, that lowers head quality in field production and thus pushes U.S. broccoli production to climates with an extended cool growing season.

Few studies have been conducted to examine variation among broccoli varieties in their development under high temperatures. Heather et al. (1992) evaluated a collection of broccoli hybrids for heat tolerance and holding ability in summer productions on Long Island, NY. These authors identified certain hybrids that yielded more marketable heads and that held their quality for a longer period of time. They found that heat stress was most damaging $\approx 3$ weeks before harvest, at which time they calculated the immature inflorescence to be 5 to $10 \mathrm{~mm}$ in diameter. Bjorkman and Pearson (1998) studied temperature arrest in the broccoli hybrid 'Galaxy' and determined that the critical heat-sensitive stage was during floral initiation, which occurs when the shoot tip has a diameter less than $5 \mathrm{~mm}$ and the apical meristem is $\approx 2 \mathrm{~mm}$. Those same authors found that the heat stress had little effect before or after the floral initiation stage. The timing of heat stress is very important in this vegetable and makes it difficult to do field selection for heritable variation in sensitivity.

\section{WHAT WILL BE THE CONDITIONS OF THE SELECTION ENVIRONMENT?}

We decided early on that the best way to ensure the necessary superoptimal heat stress conditions needed for selecting stress-tolerant plants was to grow plants in a setting with prolonged heat stress. Thus, our selection environment during summer in Charleston, $\mathrm{SC}$, is continuously hot with plants grown from seedling stages to maturity during relatively high temperatures in the field (Fig. 1). After transplanting in late May, moderate temperatures last only a few weeks during early vegetative growth. However, from late June on, daily high temperatures are $30^{\circ} \mathrm{C}$ or higher and average low temperatures seldom go lower than 20 to $23{ }^{\circ} \mathrm{C}$ through the time when trials are ending in late August (Fig. 1). Ultimately, our abiotic stress environment

\section{Average High/Low Temperatures in}

Charleston, South Carolina

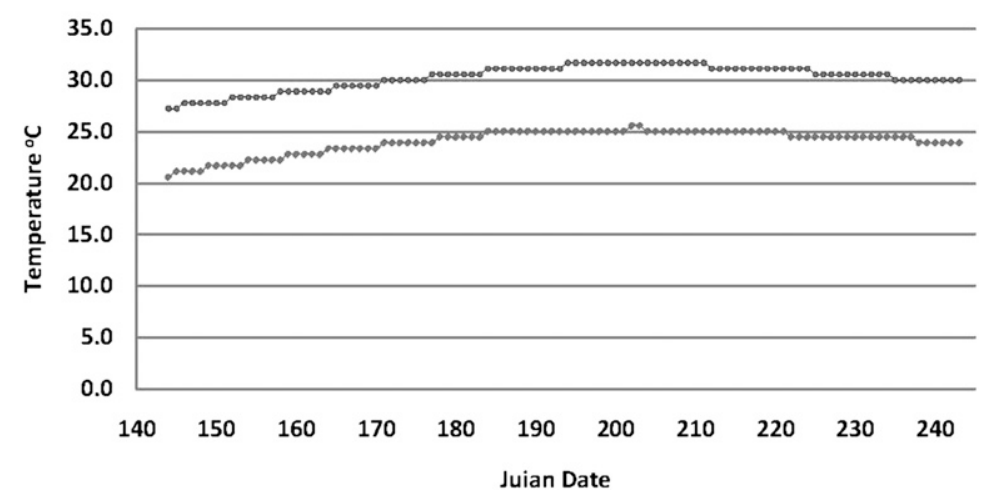

Fig. 1. Average daily high and low temperatures during selection trials conducted at the U.S. Vegetable Laboratory in Charleston, SC. Julian date 145 is 25 May and date 240 is 28 Aug.

has a characteristic temperature range that is too hot for commercial production of quality broccoli heads while being conducive to rapid growth. The relatively high night temperatures may be especially important because they may not be low enough for many broccoli cultivars to meet the chilling requirement for flower development.

It is very important that any abiotic stress be consistent so it is always possible to discriminate genetic variation for any physiological defects. Therefore, when evaluating the effects of high temperature, like in this case study with broccoli, temperatures of the test environment must be consistently hot. In general, by conventional standards, the summer environment we select at Charleston is too hot for broccoli, but it is made relatively consistent by the moderating effect of the maritime location. We remain cognizant of the possibility of higher or lower than normal temperature conditions, but lower temperatures that would be more optimal for broccoli production really do not occur in late June through August in Charleston. In years when temperatures are lower than normal, we typically make more selections with the understanding that some may not prove adequately tolerant in subsequent years. In years when temperatures are higher than normal, we take advantage of the situation, make fewer selections than normal, and scrutinize them carefully knowing they will likely perform better in subsequent years. In general, hotter than normal years allow one to select the most tolerant plants likely to occur.

\section{WHAT GERMPLASM IS AVAILABLE THAT CONTAINS THE NECESSARY GENETIC VARIATION TO INITIATE AN IMPROVEMENT EFFORT?}

When our program to breed broccoli for adaptation to high temperature was initiated in the early 1990s, all commercial broccoli hybrids available at the time were evaluated in summer field trials in South Carolina (Table 1). In addition to the commercial hybrids, two hybrids obtained from Michael
Dickson (Cornell University), bred for adaptation to summer conditions of New York State, were also evaluated. Based on performance over 2 years, the hybrids that performed best in the initial summer trials were identified (Dufault and Farnham, 1996). Although more than 60 hybrids were examined, only five were deemed to have potential merit for breeding purposes. These included 'Baccus', 'Early Dawn', 'Green Comet', 'Paragon', and 'NY4502 × 6703'. They were all subsequently selfed for several generations to create inbreds. These inbreds were in turn selected and then cross-bred to develop new segregating populations.

Since making the original selections, this project has now advanced through several cycles of recombination. This recurrent selection program has remained mostly closed. However, a few new lines have been input into the germplasm pool by crossing them with one or more inbred selections. An additional line (NY1142) was obtained from Dickson in 1996, selfed for several generations, and then crossed with a number of selected inbreds. A doubled haploid line from the hybrid Everest was crossed with selections in 2005. Our current program to breed broccoli adapted to hightemperature stress is based on a relatively small germplasm pool consisting mostly of early maturity germplasm.

\section{WHAT BREEDING SCHEME WILL BE USED TO FACILITATE IMPROVEMENT?}

A project to breed for an abiotic stress tolerance trait, similar for a project focused on nearly any trait, must consider the nature of new cultivars of the crop in question. Virtually all new commercial cultivars of broccoli are $F_{1}$ hybrids. Although the parents of individual hybrids are trade secrets kept by the seed company or other institution that makes it, most are a single cross of two highly inbred lines. In some cases, the inbred parental lines are produced by successive generations of selection and selfing. In other cases, the inbreds may be doubled haploid lines 
Table 1. Cultivars and experimental germplasm (along with the original sources of seed for each) included in 1993 and 1994 field evaluations aimed at identifying germplasm to use in the U.S. Vegetable Laboratory program effort to breed for adaptation to high temperatures.

\begin{tabular}{|c|c|c|c|}
\hline Cultivar or germplasm & Original source & Cultivar or germplasm & Original source \\
\hline Arcadia & Sakata & Green Valiant & Sakata \\
\hline Atlantic & Asgrow & Greenbelt & Sakata \\
\hline Baccus & Asgrow & Headline & Takii \\
\hline Barbados & Ferry Morse & Hi Caliber & Harris Moran \\
\hline Bonanza & Burpee & High Sierra & Asgrow \\
\hline Buccaneer & Petoseed & Landmark & Takii \\
\hline Big Sur & Asgrow & Lancelot & Petoseed \\
\hline Brigadier & Petoseed & Legend & Sakata \\
\hline Citation & Harris Moran & Marathon & Sakata \\
\hline Charade & Takii & Mariner & Petoseed \\
\hline Claudia & Ferry Morse & Mercedes & Goldsmith \\
\hline Commander & Peto Seed & Musket & Petoseed \\
\hline Cruiser & Royal Sluis & Ninja & Sakata \\
\hline Dandy Early & Park Seed & Orion & Asgrow \\
\hline Early Dawn & Asgrow & Pinnacle & Takii \\
\hline Early Emerald & Goldsmith & Packman & Petoseed \\
\hline Emperor & Sakata & Paragon & Stokes \\
\hline Emerald City & Sakata & Patriot & Sakata \\
\hline Embassy & Asgrow & Pirate & Petoseed \\
\hline Everest & Rogers & Premium Crop & Takii \\
\hline Eureka & Sakata & Sabre & Asgrow \\
\hline Excelsior & Sakata & Saga & Johnny's \\
\hline Florette & Asgrow & Shogun & Sakata \\
\hline Futura & Asgrow & Skiff & Royal Sluis \\
\hline Galaxy & Asgrow & Southern Comet & Takii \\
\hline Galleon & Petoseed & Sprinter & Sakata \\
\hline Gem & Asgrow & Sultan & Sakata \\
\hline Goliath & Stokes & Symphony & Asgrow \\
\hline Green Comet & Takii & Viking & Petoseed \\
\hline Green Duke & Sakata & Zeus & Takii \\
\hline Green Goliath & Burpee & NY2399 $\times 2403$ & Cornell University \\
\hline Green Hornet & Stokes & NY4502 × 6703 & Cornell University \\
\hline
\end{tabular}

arising from anther or microspore cultures (Gray, 1993).

Our broccoli improvement effort uses a pedigree method of breeding, in which we evaluate segregating populations in the target environment, select individuals with good performance, remove the plants from the field, and self them in an insect-free greenhouse to obtain seed for the next generation. Throughout the process, clear pedigree records have been maintained. With each successive generation of inbreeding, many lines are eliminated. However, lines that persist in the program through successive generations of selfing (e.g., from $\mathrm{F}_{6}$ to $\mathrm{F}_{8}$ ), as a result of their good horticultural phenotype and head quality under summer conditions, are used as parents to create new segregating populations. In addition, they are also used in test crosses to evaluate the potential of a given line to produce cultivar-quality hybrids. Some type of pedigree breeding method is commonly used by broccoli breeders in both the public and private sectors. Single seed descent is seldom used in this crop during early generations of selection. Without prior knowledge of how tolerance to high temperatures might be inherited in broccoli, we deemed it logical to follow the more standard pedigree approach.

In general, it is also a common practice of broccoli breeders to cross good inbreds by good inbreds when developing new hybrids. Combining ability in broccoli has not been adequately characterized. Significant general combining ability has been detected for a head development, uneven bead size, bracting in heads, and rough head surface that typically occur when conditions are too hot. We expected that progress would likely be incremental and slow; therefore, we anticipated a program that would operate over a long period with advances occurring over numerous generations. Such a program can only be undertaken in certain institutional settings; the USDA-ARS provides such conditions.

\section{FINDINGS, INSIGHTS, AND PROGRESS}

Relatively early in our program, it became evident that full-season commercial broccoli hybrids developed for Western conditions will not head in our selection environment. In the course of our summer trials, we repeatedly see that common broccoli hybrids like 'Marathon' and 'Arcadia' fail to make the normal shift from vegetative to reproductive growth that ultimately results in a primary broccoli head and instead remain vegetative (Table 2 ). The apical meristem loses dominance, perhaps in a failed reproductive transition, and lateral growth becomes excessive. Near the end of the summer, plants of 'Marathon', 'Arcadia', and many other hybrids resemble leafy green Brassicas more than they do normal broccoli plants. These observations can be explained by the fact that once transplants are 2 to 3 weeks old in our selection environment, daily low temperatures seldom go below $23^{\circ} \mathrm{C}$, the critical temperature reported necessary to vernalize broccoli and stimulate heading.

Commercial hybrids selected for Western adaptation, but widely grown in the East, exemplified by 'Gypsy' and 'Packman' (Table 2 ), will head in our target summer environment, but head quality is poor. Cultivars in this group do not appear to have a lower chilling requirement to stimulate heading. However, the chilling requirement for subsequent flower development is inconsistently met. The result is uneven bead size, roughness and discoloration of the head, and other traits that lower overall quality (Table 2).

We have been successful at increasing adaptation to high-temperature summer environments based on performance of our selected inbreds and, more importantly, hybrid combinations derived from them (Table 2). Many of the hybrids we have developed mature earlier than most commercial broccoli hybrids, producing heads in $\approx 60 \mathrm{~d}$ after transplanting. Although these USVL hybrids are early, they do not escape high temperatures because daily highs and lows already exceed 30 and $23^{\circ} \mathrm{C}$ by 3 to 4 weeks post-transplant.

Head quality is not as high for our experimental USVL hybrids compared with that typically observed with modern commercial hybrids grown in an optimal environment. They have larger flower buds and heads are not as dense as the modern commercial standard. However, at high temperatures, they do not have the flaws that make commercial material unmarketable (Table 2). Because improved performance has progressed slowly over several generations, and because 
hybrids perform better than the inbreds used to create them, the abiotic stress tolerance we are breeding for is likely to be quantitative, i.e., controlled by many genes. Future investigations in our program will confirm the mode of inheritance by examining segregating populations derived from our best inbreds.

It is likely that other efforts to breed for abiotic stress tolerance will also involve quantitative traits. In some of these cases, it is possible that marker-assisted selection may be used to improve selection efficiency. We recently developed a doubled haploid population derived from an $F_{1}$ formed by crossing one of our most tolerant inbreds with a non-tolerant inbred (doubled haploid) that produces poor-quality heads in our summer conditions. In the summer of 2011, we will evaluate 150 doubled haploid lines from this cross for adaptation to summer conditions based on head quality characteristics and we will simultaneously develop a genetic map for this population. Assuming the adaptation to relatively high temperatures is inherited quantitatively, this marker-assisted approach may identify key quantitative trait loci that we might directly select for in the future, possibly used in conjunction with a single seed descent program that might accelerate the inbreeding process.

Table 2. Trait means for days from transplant to harvest (DTH) and head characteristics including head smoothness (smooth), overall quality (quality), bead size, bead uniformity, and fresh weight for seven broccoli hybrids grown in three summer environments in Charleston, SC, in 2007, 2008, and 2009.

\begin{tabular}{|c|c|c|c|c|c|c|}
\hline \multirow[b]{2}{*}{ Hybrid } & \multirow[b]{2}{*}{$\mathrm{DTH}^{\mathrm{z}}(\mathrm{d})$} & \multicolumn{5}{|c|}{ Head characteristics } \\
\hline & & $\begin{array}{l}\text { Smooth }^{y} \\
\text { rating }\end{array}$ & $\begin{array}{l}\text { Quality }^{\mathrm{x}} \\
\text { rating }\end{array}$ & $\begin{array}{c}\text { Bead sizew } \\
(\mathrm{mm})\end{array}$ & $\begin{array}{l}\text { Bead unif. } \\
\text { rating }\end{array}$ & $\begin{array}{l}\text { Head mas } \\
\text { (g) }\end{array}$ \\
\hline Marathon & No heads & No heads & No heads & No heads & No heads & No heads \\
\hline Arcadia & No heads & No heads & No heads & No heads & No heads & No heads \\
\hline Gypsy & $61.1 \mathrm{a}$ & $3.4 \mathrm{a}$ & $6.9 \mathrm{a}$ & 1.52 & $3.3 \mathrm{a}$ & $176.7 \mathrm{a}$ \\
\hline Packman & $56.5 \mathrm{~b}$ & $3.5 \mathrm{a}$ & $7.0 \mathrm{a}$ & 1.64 & $3.0 \mathrm{~b}$ & $154.2 \mathrm{~b}$ \\
\hline USVL HY1 & $55.8 \mathrm{bc}$ & $2.7 \mathrm{c}$ & $5.3 \mathrm{~b}$ & 1.59 & $2.4 \mathrm{c}$ & $160.2 \mathrm{ab}$ \\
\hline USVL HY4 & $55.8 \mathrm{bc}$ & $2.3 \mathrm{~d}$ & $4.9 \mathrm{~b}$ & 1.78 & $2.2 \mathrm{c}$ & $155.4 \mathrm{~b}$ \\
\hline USVL HY5 & $52.6 \mathrm{c}$ & $2.3 \mathrm{~d}$ & $4.6 \mathrm{c}$ & 1.75 & $2.3 \mathrm{c}$ & $146.1 \mathrm{~b}$ \\
\hline
\end{tabular}

${ }^{z}$ Trait means (for hybrids that formed heads) followed by the same letter are not significantly $(P<0.05)$ different from one another based on analysis of variance and protected least significant difference.

${ }^{\mathrm{y}}$ Head smoothness is rated 1 to 5 with 1 = perfectly smooth bead surface, $2=$ smooth, but not perfect, $3=$ some irregularity, $4=$ very bumpy surface, and $5=$ very distorted surface.

${ }^{\mathrm{x}}$ Head quality is rated 1 to 9 with $1=$ highest quality head, $2=$ excellent quality, $3=$ very good head quality $4=$ good quality, $5=$ acceptable quality, marketable, $6=$ poor quality, nonmarketable, $7=$ very poor quality, $8=$ nearly unrecognizable as broccoli, and $9=$ not recognizable as broccoli (e.g., more cauliflower-like).

${ }^{w}$ An absence of letters indicates that no significant differences for that trait were observed among hybrids. ${ }^{\mathrm{v} B e a d}$ uniformity is rated 1 to 5 with $1=$ all beads perfectly uniform, 2 = uniform, but not perfectly, $3=$ some lack of uniformity, $4=$ irregular uniformity, and $5=$ highly irregular.

Although we have selected for stress tolerance in a single environment, our intent is to identify broccoli hybrids widely adapted to warm growing seasons. To get an indication of wide adaptability, we tested experimental USVL hybrids in Geneva, NY, where average summer temperatures do not necessarily limit broccoli productivity, but high temperature spikes often cause head quality defects. In this testing, all broccoli hybrids produced heads, but most conventional hybrids (e.g., 'Marathon' or 'Packman') had lower quality in the middle of summer, whereas the experimental USVL hybrids exhibit similar quality traits throughout the summer (Fig. 2). These initial tests indicate that our selected genotypes may be widely adapted to summer environments of the type found in the eastern United States.

It is noteworthy that although there is anecdotal evidence that broccoli produced at high temperatures may exhibit off-flavors, we are unaware of any published evidence that indicates this is actually so. At the outset, we did not expect, nor have we observed, that broccoli produced under our relatively hightemperature conditions has poor flavor. On the contrary, our own non-empirical testing indicates broccoli harvested during hot periods of summer can have good taste.

\section{CONCLUSIONS}

Breeding for abiotic stress tolerance requires persistence and good observation. Traits are multigenic with complex and easily misinterpreted phenotypes. Progress is often incremental, environmental variation large, and heritability low. However, progress can

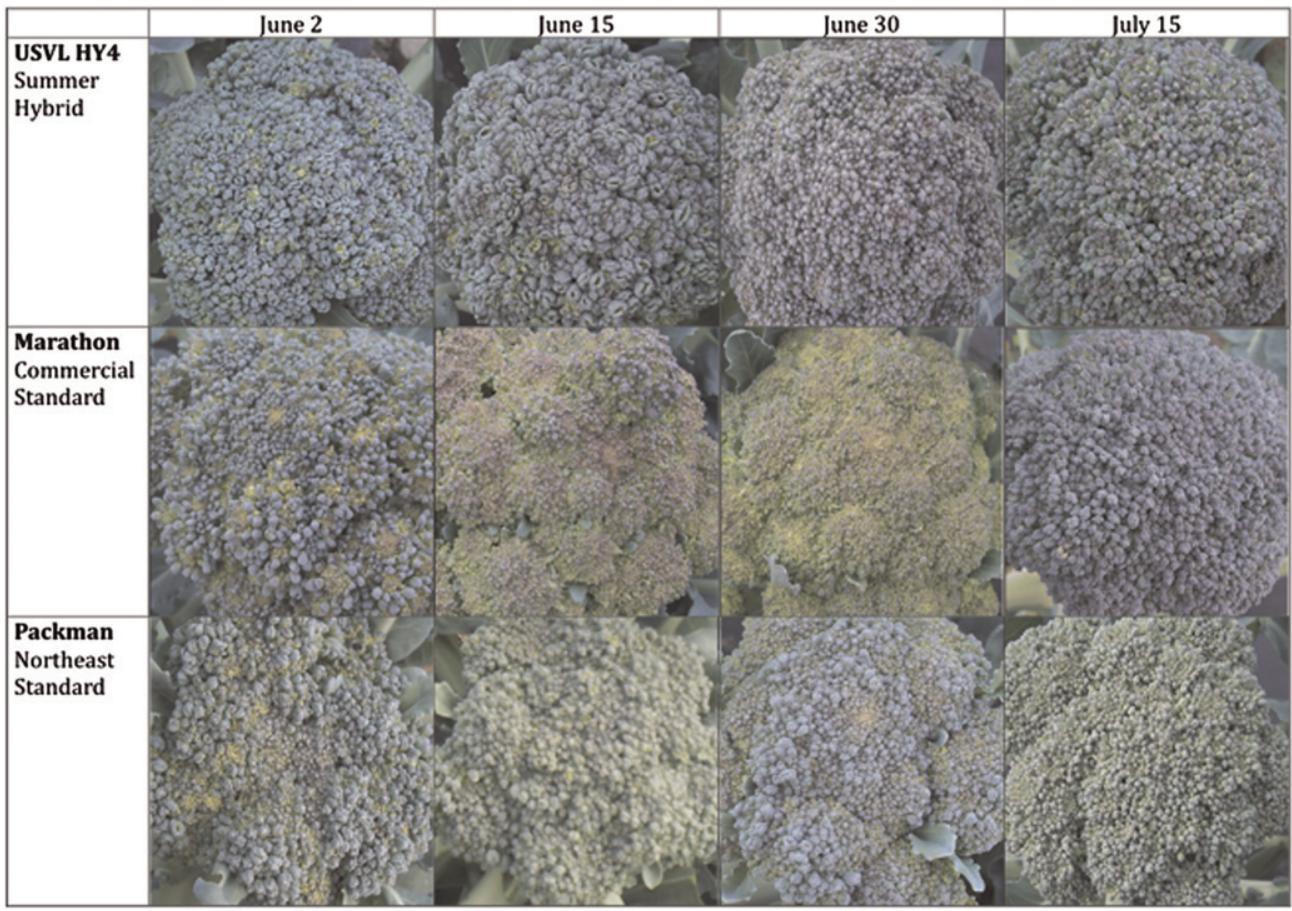

Fig. 2. Representative heads of broccoli harvested from field plots of 'Packman', 'Marathon', and U.S. Vegetable Laboratory Experimental Summer Hybrid 4 transplanted 2 June, 15 June, 30 June, and 15 July at Geneva, NY, in 2007. Heads harvested from the June plantings matured when temperatures were still hot during August and early September, whereas heads harvested from the 15 July planting matured when temperatures were cooler in late September and early October. 
be consistent by setting a clear target, keenly observing the plant response to select the more casual expression of resistance, and providing the most selective environment.

\section{Literature Cited}

Abercrombie, J.M., M.W. Farnham, and J.W. Rushing. 2005. Genetic combining ability of glucoraphanin level and other horticultural traits of broccoli. Euphytica 143:145-151.

Bjorkman, T. and K.J. Pearson. 1998. High temperature arrest of inflorescence development in broccoli (Brassica oleracea var. italica L.). J. Expt. Bot. 49:101-106.

Dufault, R.J. and M.W. Farnham. 1996. Broccoli varieties for spring, summer and fall in coastal South Carolina. 1995-96 Clemson University Vegetable Report. p. 11-12.
Fontes, M.R. and J.L. Ozbun. 1972. Relationship between carbohydrate level and floral initiation in broccoli. J. Amer. Soc. Hort. Sci. 97:346-348.

Fontes, M.R., J.L. Ozbun, and S. Sadik. 1967. Influence of temperature on initiation of floral primordial in green sprouting broccoli. J. Amer. Soc. Hort. Sci. 91:315-320.

Gauss, J.F. and G.A. Taylor. 1969. Environmental factors influencing reproductive differentiation and the subsequent formation of the inflorescence of Brassica oleracea L. var. italica, Plenck, cv. 'Coastal' . J. Amer. Soc. Hort. Sci. 94 : 275-280.

Gray, A.R. 1993. Broccoli: Brassica oleracea (Italica Group). In: Kalloo, G. and B.O. Bergh (eds.). Genetic improvement of vegetable crops. Pergamon Press, Oxford, UK.

Heather, D.W., J.B. Sieczka, M.H. Dickson, and D.W. Wolfe. 1992. Heat tolerance and holding ability in broccoli. J. Amer. Soc. Hort. Sci. 117: 887-892.

Hulbert, S.H. and T.J. Orton. 1984. Genetic and environmental effects on mean maturity data and uniformity in broccoli. J. Amer. Soc. Hort. Sci. 109:487-490.

Maynard, D.N. and G.J. Hochmuth. 2007. Knott's handbook for vegetable growers. 5th ed. John Wiley and Sons, Inc., Hoboken, NJ.

Miller, C.H., T.R. Konsler, and W.J. Lamont. 1985. Cold stress influence on premature flowering of broccoli. HortScience 20:193-195.

United States Department of Agriculture, Economic Research Service. 2010. Vegetables and melons yearbook.

Wurr, D.C.E., J.R. Fellows, K. Phelps, and R.J. Reader. 1995. Vernalization in calabrese (Brassica oleracea var. italica) - A model for apex development. J. Expt. Bot. 46:1487-1496. 